Exploring perceptions and attitudes towards teaching and learning manual technical drawing in a digital age.

\begin{abstract}
This paper examines the place of manual technical drawing in the $21^{\text {st }}$ century by discussing the perceived value and relevance of teaching school students how to draw using traditional instruments, in a world of computer aided drafting (CAD). Views were obtained through an e-survey, questionnaires and structured interviews. The sample groups represent professional CAD users (e.g. engineers, architects); university lecturers; Technology Education teachers and student teachers; and school students taking Scottish Qualification Authority (SQA) Graphic Communication courses. An analysis of these personal views and attitudes indicates some common values between the various groups canvassed of what instruction in traditional manual technical drafting contributes towards learning. Themes emerge such as problem solving, visualisation, accuracy, co-ordination, use of standard conventions, personal discipline and artistry. In contrast to the assumptions of Prensky's thesis (2001a\&b) of digital natives, the study reported in this paper indicate that the school students apparently appreciate the experience of traditional drafting. In conclusion, the paper illustrates the perceived value of such learning in terms of transferable skills, personal achievement and enjoyment.
\end{abstract}

Key words/phrases

$C A D$; curriculum change; manual technical drafting; new technologies; perceived value of learning; student attitude; views on school curriculum content;

\title{
INTRODUCTION
}

Prensky states, 'Digital immigrant instructors, who speak an outdated language (that of predigital age) are struggling to teach a population that speaks an entirely new language' (2001a. 
p4). He urges educators to consider two kinds of content which he describes as 'legacy' and 'future'. 'Legacy content' is what is thought of as the traditional curriculum. This, he states, will have to be selectively reduced and some aspects will remain as important. He suggests that some, such as Euclidean geometry, will be considered less important, much as Latin and Greek. He describes 'future content' as largely digital and technological and he includes here aspects such as politics, sociology and ethics. He notes that both legacy and future content should be taught in the language of digital natives. (Prensky, 2001b.)

The contemporaneousness of school Graphical Communication courses (Scottish Qualifications Authority, SQA, 1991, 1999) is a subject of debate in Technology Education staffrooms and student teacher common rooms in Scotland. Issues have been raised that question the relevance and validity of the Graphical Communication curriculum content. Technology education curriculum reviews have resulted in an increased requirement for the teaching of computer aided graphics, including computer aided drafting, specifically 2-D CAD. Instruction in manual technical drawing remains a central component of the Graphical Communication courses.

Some technology education teachers feel that they are involved in teaching a redundant subject. They believe that, in a world of CAD, there is no place for drawing boards and set squares. Others are adamant that school students need to 'know the basics' of technical drawing before working in a CAD environment. This is not a debate that is restricted to Scottish education. For example, Wiebe \& Clark (1997) and Bussey et al (2000) also discuss criticism regarding the relevance of teaching a highly specialized graphics language of manual drafting skills to the broad population of school students in parts of the USA.

There are those in higher education and industry who are concerned about the poor standards 
of CAD drawings produced by engineering and design students, and workplace recruits. Some of the literature, to be discussed in more detail in the next section, suggests that the demise in standards is due to a lack of understanding of basic geometric construction and the conventions of drafting skills that underpin CAD. In order to determine if there was any substantiation to such critique, a wide range of views were canvassed for this case study from those working in industry, lecturers, teachers and student teachers and school students. This paper examines the place of manual technical drawing in the $21^{\text {st }}$ century by discussing the perceived value and relevance of teaching school students how to draw using traditional manual drafting, in a digital age.

In order that the reader can contextualise the values and attitudes explored, the first section of the paper summarises some of the available research literature. The second section describes the current school curriculum for SQA Graphic Communication. The third section provides an outline of the method adopted to gather the views of the four key sample groups. This is followed by an illustrated discussion of the survey responses. Each sample group is explored in turn. The emergent themes are discussed.

It should be noted that the focus for computer based experience, for the purposes of this study, is with computer aided drafting, 2-D CAD, only.

\section{RELATED RESEARCH LITERATURE}

Field (2004) argues that knowledge of drafting develops thinking in three dimensions (3D) and communicating in two dimensions (2D). He recognises the difficulties learners have in moving from two dimensionally dominant interactions into three dimensions through the principles of drafting to interactive solid modelling. He suggests that to overcome this difficulty, students require understanding of some solid geometry through drafting and courses in plane geometry which cover applied geometry as well as logic. He is concerned 
that too many $\mathrm{CAD}$ professionals have weak spatial intuition and reasoning and often create and accept flawed geometry and are reluctant to tackle changes that require modification of geometry. He suggests that CAD systems are too successful due to being 'too easy to use'. Users need to display greater criticality in application. He makes the case for the additional requirements of education for $\mathrm{CAD}$ and proposes that instruction in $\mathrm{CAD}$ alone cannot replace the basic technical drafting foundations. He maintains that engineering curricula should include solid geometry and implies experience in drafting and instruction in descriptive geometry is required to develop the necessary level of spatial reasoning to be an effective and efficient user of CAD. He wants learning to be more than, what he calls, 'picks and clicks' of specific software packages. Designers and engineers would then be more able to understand the limitations, and the capabilities, of CAD systems more usefully. This is supported by Leopold et al (2001) who observe that CAD users who have had hands-on problem solving through descriptive geometry and graphics taught using 3D physical models have improved spatial abilities. They argue that such experience has a positive impact on their understanding of CAD compared to those who have learned CAD systems only. They conducted a comparative study involving university students of architecture and various engineering disciplines. The study involved four groups of students none of whom had prior learning in related technical graphics or drafting. The groups received different courses ranging from the most comprehensive comprising instruction in manual technical drafting and descriptive geometry and general use of instruments to solve spatial tasks, through to those who received instruction with CAD only, no instruction in manual technical drafting, descriptive geometry, nor in the use of instruments or sketching. This study develops the work of Sorby \& Gorska (1998) who claim that 'hands-on sketching and drawing tend to improve spatial skills more than courses that stress Computer Aided Design methods'. They suggest that the physical nature of the drafting experience develops a deeper understanding of the meaning of lines and symbols on a page and helps to develop the ability to make 
mental conversions into $3 \mathrm{D}$ realities. The interpretation necessary between $2 \mathrm{D}$ and $3 \mathrm{D}$ and vice versa involves more than the ability to follow techniques and procedures to 'solve the problem'. Manual drafting encourages this critical spatial thinking and visualisation. Reffold (1998) writes on issues arising from the decision to teach undergraduate engineering students on CAD. None of his students had any prior experience of manual technical drawing. His approach was to have students work through CAD operational exercises prior to learning about the purposes of engineering drawing and the concept of projection. Increasingly realistic contexts were given as exercises. These exercises demanded progressively more detailed knowledge of conventions and drawing types. However, he still identified particular problems with the 'surviving student'. He describes the surface learner syndrome and observes a copying culture which is prevalent at the expense of genuine understanding developed through deep learning ( Entwhistle 1981; Marton \& Säljö 1976).

Olkun (2003) discusses the role of geometric activities in enhancing spatial abilities of students and suggests that that not enough time is allocated to transformational geometry within the traditional mathematic curricula. He discusses the importance of physical and mental manipulation and representation in $2 \mathrm{D}$ and $3 \mathrm{D}$ to develop both the ability to solve spatial relation problems and more complex spatial visualisation tasks ( $\mathrm{p} 2)$. He proposes that since representation of $3 \mathrm{D}$ objects by $2 \mathrm{D}$ diagrams demands understanding of conventions that involve mental integration or mental disassembly, those that have the language of the conventions will be in a position to practice and improve. Thus engineering drafting affords the learner the means to develop in terms of cognitive complexity. He argues for traditional technical drafting convention and associated geometry to be taught to the whole student population.

McCardle (2002) identifies a significant lack of knowledge of engineering drawing among 
his undergraduates. He observes a drop in manual drawing standards over recent years. Even students with some prior experience in technical drafting displayed a very limited working knowledge of British Standards and understanding of the need to follow conventions. He argues that taking away the basic drawing skills and the formal language of engineering drawing is like making mental arithmetic redundant (p126). McCardle concludes that the value of manual technical drawing lies in the development of visualisation and manipulation of views $2 \mathrm{D}$ and $3 \mathrm{D}$, issues of cognitive modelling and transposing images; line quality, accuracy, basic geometry involved in constructing shapes and clarity through application of accepted conventions.

Bhavnani \& John (1996, 1997), Bhavnani et al (2001) and Chester (2004) explore why CAD users tend to use CAD in a way that resembles manual drafting, as an electronic drafting board. A review of $\mathrm{CAD}$ instruction and operation manuals revealed a concentration on the acquisition of computer command skills and not the strategic, cognitive skills that develop the deep understanding and capability required for CAD. The terms used in training manuals are from traditional drafting terminology and the focus is on procedures and tools/ commands and locations. This results in the adoption of suboptimal procedures in approaches to the new media. A new pedagogical approach is needed to address the issues that arise from the limitations of such command based, operational training. Bhavnani \& John (1996) contrast the quality of the 'end product' between the two drafting systems of manual and computer aided drafting and link their observations to their analysis and comparison of guidance texts and teaching approaches used to develop manual technical drawing skills and tools. They note the emphasis on the haptic, physicality of feedback from pencil and paper to eyes and brain. Detailed advice is given regarding the importance of accuracy and quality in manually produced technical drawing and the ways this can be achieved. The use of the wrong procedure or strategy results in a low quality drawing which is easily recognised as low 
quality drafting and an inaccurate solution. They argue that since 'there is such a strong causal relationship between technique and quality, and because the flaws are publicly visible, drafters tend to be highly motivated to improve technique' (1996, p336). They argue this causal relationship is absent in CAD. A CAD drawing is clean and looks accurate. There is no visible indication that the drawing was produced by a suboptimal strategy. As a consequence of this there is little motivation to look neither critically at the outcome nor at the process of creating the drawing. It is only when poorly constructed CAD drawings are shared and manipulated by others that they are 'found out', and cause problems for others who are required to manipulate the geometry. If no feedback from others or no experience of failure or demands for remediation, CAD users continue to use suboptimal and ineffective strategies. Bhavnani \& John (1996) cite Bietz et al (1990) who note that students who have passed the required proficiency tests in CAD produced better and more complete drawings with less effort using drafting boards, paper and pencil than with CAD system. CAD operators can perform poorly, display frustration and reduced performance in creativity due to the complexity of commands, input parameters and requirements of the system. Haapasalo (2000) states, 'Difficulties and conscious effort with CAD transfers the attention and concentration away from the object to be designed. The more conscious the effort the user interfaces requires the more harmful for creativity'. Hand-eye co-ordination of drawing allows the subconscious memory to flow more naturally and faster.

Ullman et al (1990) argue the importance of both formal drafting and informal sketching as necessary problem solving skills required at various stages of the mechanical design process. They note that not much is known about how humans represent information in memory, but suggests that internal representation is different from however we choose to represent it externally, through whatever medium is chosen and whatever graphic convention used. There is little literature available about the cognitive load involved in transforming internal 
workspace to the external workspace outside the mind. There is limited understanding how we store and manipulate visual information. However, it is recognised that the cognitive process used to draw a line with a pencil is different from that of specifying the end points for CAD representation. Psychology tells us that the 'internal memory' has a limited capacity is powerful and fast, is used for visual perception, drawing and creation. Whereas the 'external memory' has infinite capacity, access is slow and not direct. It needs a cue for retrieval. The additional cognitive load to implement CAD systems currently is slowing down design process. Icon and menu selecting add steps in image creation. The development of sketching, drafting skills and conventions aid representation of abstract and concrete concepts. The designing process can be limited when there is limited ability to use graphics as a cognitive extension.

Gagel (1997) explores technical drawing as a universal graphic language that has been refined over time and has embedded within it aspects and knowledge of symbolic, cultural, utility, cognitive nature, much as any language, literacy and communication. There are the conventions, shared community processes and recognised applications of any developed language. This is a physical mode which aids cognition and through which visualisation and innovative problem solving can be made explicit. As with any language it helps one to share ones thoughts with others or clarifies and articulates one's own thinking. Gagel suggests the computer has displaced the traditional drafting which placed great emphasis on quality of drafting skill often at the expense of developing the deeper thinking knowledge and articulation that represent true language skills. Gagel argues that a relevant technology curriculum would take as its primary focus 'identifying, capturing, relaying technical information in graphic form accurately, completely and in accordance with standard conventions' of the language which, he states, have hitherto only occurred in advanced studies of technical drawing. His argument is that CAD displaces the need to teach the more 
instructional aspects of technical drawing, i.e. the manual drafting skills are eliminated by CAD. Therefore the more cognitive elements of technical drawing can be introduced earlier thus freeing up time for the development of technological knowledge and creativity.

These studies recognise the contribution manual technical drafting and descriptive geometry makes towards the development of spatial abilities and the understanding of conventions of the language of engineering drawing. They also stress that the differences in strategy and thinking between manual drafting and CAD needs to be made more explicit in order to encourage the CAD users to 'design the drawing' and appreciate the associativity of the elements within the images to be represented. They recognised the need to 'see' and create entities in a new and in a different way. In this way users can make more efficient use and exploit the advantages of CAD. To sum up, there seems to be a consensus (e.g. Bhavnani \& John 1996; Gagel 1997; Reffold 1998; Chester, 2004; Field 2004) that the teaching of CAD requires a rethink and that greater importance should be given to the teaching of strategies rather than commands and features. Many (e.g. Ullman et al.1990; Devon et al. 1994; Bhavnani \& John 1996; Sorby \& Gorska 1998; Haapasalo, 2000; Leopold et al. 2001; Olkun 2003; Field 2004; McCardle 2004) have argued that traditional manual drafting is an effective means of developing spatial visualisation skills and improves performance in spatial reasoning. The literature recognises the importance of developing a working knowledge and understanding of descriptive and solid geometry, and spatial intuition and reasoning in order to be a proficient and informed user of CAD.

\section{CURRICULUM CHANGES TO PRESENT DAY}

The introduction of CAD, and computerised manufacture, challenges the whole premise of drafting and the need to learn the principles of drafting (manual or other). What are the consequences of this for secondary school and beyond? The experiences of manual drafting courses were devised to help students interpret isometrics, perspectives, and exploded-views 
to create orthographic and vice versa. The learning was to be illustrative of the conventions and skills integral to product development and reflect the industrial world. A shift in focus from board to computer aided drafting, to computer aided solid modelling of design thinking and CAD./CAM has not been reflected in the SQA curriculum.

There have been some changes to the school curriculum in Scotland as an attempt to keep abreast of changing needs and attitudes of education and industry. However, manual Technical Drawing has survived various Technical Education curriculum reviews (1972, 1983, 1991, 1994, 1999). Scottish Education Department Circular 1101 (SED, 1983) proposed that the Technical Drawing Certification courses were to be phased out and selected aspects subsumed in other Technical Education courses. Strong reaction from the Technology Teachers' Association (TTA), Scotland, with support from industry, reversed this decision. 'Technical Drawing' continued, until 'Graphic Communication' Standard Grade (1991) and Higher Grade (1994) were introduced. Although these new courses had a different emphasis, engineering drawing and geometric drawing remained within the syllabi. CAD was incorporated for the first time. So too were 'illustration and presentation' skills, to broaden relevance and provide a range of contexts for the application of communication methods. Subsequent reviews for SQA Higher Still (1999) resulted in Intermediate 2 and Higher Graphic Communication replacing the previous syllabus.

Standard Grade Graphic Communication has remained unaltered since it was written in 1991. It focuses on a variety of graphic media and communication techniques in the context of graphics as an international language. The two year course is about reading, interpreting and communicating graphically; developing knowledge and understanding of the fundamentals of graphics (e.g. geometrical construction, convention, drawing type); selecting, organising and presenting information graphically; developing the ability to use a range of drafting 
techniques and developing an expertise in computer aided graphics (CAG). The use of computers is an essential part of the course.

Intermediate 2 and Higher Graphic Communication (SQA, 1999) have similar aims. Specifically, the development of knowledge and understanding of graphics, in particular, technical graphics in the context of construction, engineering and the consumer/ market place. 'The creation and interpretation of drawings are generic skills useful in employment and as life skills in a world where communication increasingly relies upon graphics.' (Intermediate 2, 1999, p1) The intention is that the courses develop knowledge and skills in sketching and drawing items in orthographic and pictorial projections, using both manual and computer-aided techniques, with an appreciation of the need for clarity, accuracy and knowledge of relevant British Standards. None of these courses have any specified assessable components or learning outcomes regarding design or designing. The weighting of SQA assessment suggests the importance of manual technical drawing abilities.

In summary, manual technical drawing remains an important component of Technology Education in Scotland. This suggests that learning gained from experiences of traditional technical drawing is considered to be of value.

\section{METHOD OF STUDY}

The inquiry into the value of manual technical drawing was instigated initially when the question of subject redundancy was raised by several Technology teachers on the National Qualification ‘smartgroup' web-ring for all teachers teaching SQA Graphic Communication ( $\mathrm{n}=212$ users) (http://www.smartgroups.com/group/group.cfm?GID=856658). It was suggested that, in the $21^{\text {st }}$ century, the world of work no longer used drawing boards so why should schools continue this practice. One particular student teacher, an ex-engineer, was so surprised schools continued to teach manual technical drawing he adopted the topic as a small research 
based assignment (Hughes, 2003). Therefore, the first stage of this study set out to explore the views of those who used CAD as part of their industrial and commercial work. The table below summarizes the design of the research method adopted. Each phase serves to inform the subsequent phase.

\begin{tabular}{|c|c|c|c|}
\hline Phase & Method & Sample & Objective \\
\hline 1 & $\begin{array}{l}\mathrm{Y} / \mathrm{N} \text { e-survey 'should } \\
\text { manual technical } \\
\text { drawing be taught in } \\
\text { secondary schools?' } \\
\text { Open-ended reasons } \\
\text { invited Content analysis } \rightarrow \\
10 \text { themes } \rightarrow 4 \text { questions } \\
\text { used to inform } \\
\text { questionnaires \& interviews }\end{array}$ & $\begin{array}{l}\text { A: Industrial CAD operators and } \\
\text { professionals (architects, engineers, } \\
\text { CAD managers etc) } n=374 \text { Received } \\
\text { extended responses } n=46 \text { ( } 13 \% \text { of } \\
\text { respondents) }\end{array}$ & $\begin{array}{l}\text { Gauge views of industry } \\
\text { related CAD } \\
\text { professionals. Gather } \\
\text { Quantitative data on } \\
\text { number of companies } \\
\text { using only manual } \\
\text { drafting; Combination of } \\
\text { CAD and manual; CAD } \\
\text { only. Identify common } \\
\text { themes in extended } \\
\text { individual responses. }\end{array}$ \\
\hline $2 \mathrm{a}$ & $\begin{array}{l}\text { structured e- } \\
\text { questionnaire; open } \\
\text { questions; }\end{array}$ & $\begin{array}{l}\text { B: university lecturers (engineering \& } \\
\text { product design specialists ) } n=6\end{array}$ & $\begin{array}{l}\text { Explore views of those } \\
\text { who work with students } \\
\text { who require related } \\
\text { knowledge \& } \\
\text { understanding and skills }\end{array}$ \\
\hline \multirow[t]{2}{*}{$2 \mathrm{~b}$} & structured interview; & C: technology teachers $n=8(2-28$ & Explore views of new \\
\hline & $\begin{array}{l}\text { structured } \\
\text { questionnaire; open } \\
\text { questions; }\end{array}$ & $\begin{array}{l}\text { years experience) D: PGDE student } \\
\text { technology teachers (previously } \\
\text { engineers, architects, product designers, } \\
\text { etc) } n=14 \text { ( } 10 \% \text { of national cohort of } \\
\text { technology student teachers ) }\end{array}$ & $\begin{array}{l}\text { recruits to teaching } \\
\text { profession who will } \\
\text { responsible for } \\
\text { curriculum presentation } \\
\text { and development in near } \\
\text { and longer term future }\end{array}$ \\
\hline 3 & $\begin{array}{l}\text { Constructs 'mined' } \\
24 \text { constructs/ } 3 \text { open } \\
\text { questions }\end{array}$ & $\begin{array}{l}\text { E; school students, on SQA Graphic } \\
\text { Communication courses, } n=115(14- \\
18 y r s ;(1 \% \text { of national cohort } \\
\text { presented for examination) Standard } \\
\text { Grade (S3 \&4), Int } 2 \text {, Higher Grade, } \\
\text { Advanced Higher ) from secondary } \\
\text { schools, } n=327 \% \text { of the sample } \\
\text { studying Intermediate } 2 \text { (S5), Higher } \\
\text { (S5) or Advanced Higher (S6). }\end{array}$ & $\begin{array}{l}\text { Gauge views of school } \\
\text { students undertaking the } \\
\text { courses at various levels, } \\
\text { range of experience with } \\
\text { both drawing board and } \\
\text { computer drafting. }\end{array}$ \\
\hline
\end{tabular}

Table 1: Method summary chart

Phase 1 The Industrialists (sample group A) An e-survey survey invited readership of the 'Cadalyst' magazine [posted through www.cadalyst.com (April/ May2003)] to 'vote' (yes/ no) whether school students should still be taught manual technical drawing. They were invited to qualify their opinion. Respondents were also asked to indicate whether they 
worked in a company which relied solely on CAD, both CAD and drawing boards or drawing boards only. Many of the respondents were USA based due to the readership of the magazine. It is acknowledged that e-surveys have limitations and can contain bias towards those who have strong opinions to one degree or the other. However, the number of industrial respondents indicated an interest in the school based issue and the views sent to the researcher provided useful illustrations for the context of this attitudinal and perception based study. The responses offered were analysed and categorized to help inform phase 2 of the study.

Phase 2a and 2b The Educators (sample groups B,C \&D)

The themes, categories and questions emerging from phase 1 served to inform the design of the survey and interview schedule devised for next three sample groups.

Group B, University lecturers: e-mail questionnaire which was circulated to specialists university lecturers working with engineering and design students

Group C, Technology Teachers: structured interviews, using the same questions as email questionnaire, were conducted with their technology education teachers

Group D, Technology student teachers: A questionnaire survey was also distributed to student teachers nearing the end of a one year Professional Graduate Diploma in Education ( PGDE), specialising in Technology Education. The cohort comprised a range of professionals many of whom were familiar with CAD from their previous careers. However, it may have been several years since they last worked on a drawing board, if ever, and for the purposes of their teaching they have to develop skills in manual drafting and an understanding of geometric construction required by the syllabi.

Phase 3 The School students (sample group E) The themes and constructs that emerged from the previous surveys with industry professionals, lecturers and school teachers, were developed to devise a 4 point likert scale questionnaire to explore the value the school students themselves assigned to manual technical drawing in relationship to CAD. The sample group comprised those at early stages of their SQA courses (i.e. novice CAD and drawing board users at secondary years S3 -S4 /14-15year olds) through to senior students undertaking SQA Advanced Higher Graphic Communication (those at secondary year S6 / 17year old). Having studied Graphic Communication for 4 years, they can be considered 
experienced in both board and computer work. $27 \%$ of the sample group had successfully completed the Standard Grade Graphic Communication course prior to participating in the study. These students have had a minimum approximately 40 hours experience of various computer aided graphics tasks (including CAD). The questionnaires were completed within class time to encourage responses from all students.

The students were asked to indicate the degree to which they agreed or disagreed with 24

constructs offered (Appendix I). The students were also asked three open questions.

Why should you learn to use CAD? boards?

What were the advantages of using paper, pencils, drawing instruments and drawing

What were the disadvantages of using with paper, pencils, drawing instruments and drawing boards?

\section{SUMMARY OF FINDINGS}

This section provides a summary of the attitudes and views of the sample groups from industry, higher education lecturers, teachers, student teachers and school students to gauge their thoughts on the value of learning manual technical drawing. The themes that initially emerged from the evidence gathered were categorised as follows:

1 understanding, thinking, spatial awareness, visualisation, relationships of views;

2 basics of conventions, standards, layouts and scale;

3 control, accuracy, neatness and general discipline;

4 motivation, ownership, artistry.

To illustrate, each of the sample groups are taken in turn and a synopsis of thefindings is given.

Views from Industry (sample group A)The survey indicated that only 1 in 5 companies represented by the respondentscontinue to do manual technical drawings. Of the sample, $(n=374) 87 \%$ expressed theview that students should first learn to draft with paper and pencil before progressingto $\mathrm{CAD}$. The majority of the extended individual responses indicated 
support forteaching the fundamentals of orthographic drawing through manual technicaldrawing. Manual technical drawing was generally viewed as providing a solidgrounding in terms of knowledge and understanding of drafting as a concept. Theyargued that this conceptual understanding seemed to facilitate faster access to thelearning required for CAD. Citing personal observation and on-the-job trials withnew recruits, some argued that it was easier to teach CAD when the novices had priorlearning from board work experience. This prior experience seemed to allow thelearner to focus on the commands and technicalities of the software. They hadacquired the visualisation skills to cope with the virtual environment and had learned 'how to see'. Some respondents, while acknowledging the advantages of $\mathrm{CAD}$, valued the discipline, the haptic nature, the artistry and enjoyment of the manualdrafting experience

The following comments are typical and indicative of the categories that began toemerge from analysis.Respondents argued that manual drafting made a significant contribution in terms ofknowledge and understanding. E.g.

"Manual drafting teaches the most fundamental approaches to graphics and geometry, which is imperative to a learning foundation. ... can be quite proficient in operating the software, but their knowledge of what they are drawing is limited and the quality of the geometry in the model is poor. There is a significant amount of understanding that comes from plotting by hand, with pencils and paper. Not only do you have the tactile experience, and a more direct connection of hand to eye to brain, but you also become aware of the graphic representation. ...” architect

There was agreement that manual technical drafting developed skills in spatial awareness, visualisation, planning, 'thinking things through'. E.g.

“... the skills of hand sketching and mentally visualising an object can only be adequately learned by doing it with pen or pencil. Once the fundamentals are mastered, then the students can learn to draw using a computer.” Naval architect 
"Drafting teaches the draftsman (sic) to sit down and think about how a drawing should be laid out and what drawings should be required. With CAD it is too easy to just start drafting and see where it takes you. Sitting down for 10-15 mins to plan and drawing as you would with manual drafting can save headaches and time down the road." assistant clerk of works, local council

There was some concern that "selecting, pointing and clicking" had implications for the depth of knowledge and understanding that was being developed and subsequently the ability to apply critical capabilities to problem solving was limited. E.g.

\footnotetext{
“A CAD drawing is simply a graphical representation of the underlying data. It has the potential to be a superior resource to manual drawing, but only if the underlying data had information content. If there is inconsistency in the layering, line weight, line type or geometry, there is little information that can be extracted because of the noise generated by the lack of consistency..... In the long run, an ability to access the information content can be more important than the sheer speed of creating geometry in a CAD program." co-author of national standards USA (CSAB78.5) on CADD

"I think very often they get caught up in learning how the tool works, but aren't able to use it properly...” IT/CAD manager (architect)
}

Respondents argued that manual technical drafting contributed towards the development in terms of 'speed of learning' and 'standards and conventions'. E.g.

“...people who learn the basics on a drafting board, seem to learn computer drafting a lot faster and follow standards." Mechanical design engineer

“... younger draftsmen(sic) working for me who have never done any board drafting... lack the finesse ...Everything is one or two line weights and it's hard to determine the object drawn from the dimensioning. Those who have had board drafting, either in school or on the job training, seem to create easier reading drawings/ maps. I think it falls in the realm of being able to think through the arithmetic/ mathematics before using the calculator."

Draftsperson

The respondents thought that manual technical drafting instilled quality, care, artistry, 
discipline and control in the draughtsperson. E.g.

“...The people we have hired, in the last few years, have only ever used the computer. I find the quality of their work is very lacking. Manual drafting seems to instil care into what you are working on. Maybe it's because if you make mistake, it is a lot more work with pen and ink to correct it than with a computer." Local Council officer, engineering dept

“...When a hand lays upon a pencil and the pencil upon the paper, a connection to the work exists on an ethereal level. Can you feel the weight of a line on the paper? On a computer? Not that it makes a big difference, but having learned to draft by hand teaches you to be deliberate in your work. Computers offer instant correction and foster laziness. Hand drafting demands a precision and revision and coffee stains. Computer drafting offers speed, redundancy, crispness of line and more flexibility. As a production tool it far exceeds manual drafting. However as an educational tool, as a philosophy to be applied to design, hand drafting offers much more than a computer ever will......." Architect

“...There is an artistic element that is missing if a student does not learn manual drafting. This element is difficult to learn through just sitting at the computer. I have supervised several CAD drafters that have never done manual drafting and have had to teach them the artistic element that was missing, which improved their work and work habits." design services coordinator.

“...I believe manual drafting teaches a person that drafting is an art. There is a reason there are line weights and styles. I began hand drafting years ago and would not think of placing a note overlapping another note. However, my colleagues (who do not know how to hand draft) do not think twice about letting something like that slide. I love computer drafting and the speed has helped me do many things. But it allows for sloppy drafting in place of meeting a deadline..." CAD manager

Throughout the analysis of the survey responses it was evident that a good understanding of what was being drawn was important and not merely the ability to create entities. This observation echoes observations of draftsmen in the drawing offices throughout the $1800 \mathrm{~s}$. It was thought possible to discern a potential engineer from one who would remain in the 
drawing office for the rest of his life, early in a draftsman's apprenticeship (Brooker, 1979). The ability to develop problem solving and decision making skills pertaining to the act of communication through deep understanding, transferability, organisation of content together with the ability to diagnose faults and problem solve was valued then as it is today.

In summary, those working in an industry related CAD environment were not suggesting a return to the drawing boards. However, they felt that the value of teaching manual technical drawing lay in developing associated knowledge and understanding of the concepts and technicalities of drafting (projections, layout, related views and positions; geometry, line weight and other conventions; notes/ lettering; drawing type; density/ depth.) This was easier to comprehend when dealt with as distinct from learning the software. The advantages of CAD were acknowledged and enjoyment of working in the virtual environment was also evident.

E.g.

"I am in favour of manual drafting as a stepping stone to learning CAD... learning the basics on the board gave me a full understanding of what I was creating in CAD. I shudder to think of how it would be going back to the board. CAD is without doubt, far superior to the old drafting board. The ease of creating, copying and changing cannot be beat by anyone on drafting board... I always enjoyed board work and I enjoy, much more, using CAD."

draftsperson

There was a high level of awareness and appreciation of attitudinal values developed through manual drafting. These can be categorised in terms of: perseverance, patience, discipline, appreciation of the advantages of new technologies, care for precision, importance of planning, artistry in composition / layout for purposes of clarity and personal satisfaction. 
survey shared the concerns of the industry professional that the students they worked with seemed to have a poor understanding of the fundamentals of constructing a drawing, lacked of confidence in sketching, and lacked appreciation of the need to comply with rules, conventions and standards. The students seemed to be seduced by the CAD, placing great emphasis on creating a nice CAD graphic even though the design concept was flawed. CAD seems to force the students to firm up on their designs too early without the necessary level of exploration of what was being drawn.

As with those from industry, there seemed to be consensus among the sample group of lecturers that learning fundamentals of technical drawing manually prior to learning CAD had some advantages. It was observed that those who came to university with a grounding in technical drawing fared better with $\mathrm{CAD}$, more confident in producing layout drawings and were also better at sketching. Here too it seemed that a separation of learning 'drafting fundamentals' and software was an easier, and a more useful, approach. E.g.

"I think manual skills should still be taught as it is easier to learn the rules and constraints without the complication of a CAD system."

\footnotetext{
"In relation to formal drawing standards-the students seem less familiar with the standard notation if learning on CAD rather than manual -this is probably because the CAD system does a lot for them and they simply accept what it gives whether it complies with standards or not."
}

Attempts to teach university students on CAD, bypassing manual drafting, have not had success. The lecturers indicated that they felt the steep learning curve of CAD detracted from understanding the basics. The students tended to focus on learning the commands at the expense of understanding and the development of any cognitive modeling abilities. They seemed to accept what was given by the software uncritically. Observations of lecturers indicate that students lacked understanding of some fundamental aspects of engineering 
drawing, projections, conventions and geometric construction.

Views of Teachers (sample group C) The majority of the teachers agreed that it was important that school students have experience of working on the drawing board to develop manual technical drawing prior to learning CAD. It was suggested that some students have difficulties with visualization. Working on the drawing board was thought to facilitate 'seeing' for understanding e.g.

“... able to visualise better - due to more order- better chance to learn, to really understand.” One teacher admitted that students can be good at CAD but have no underpinning understanding. He continued that "they need to be able to analyse and have understanding...but I see it as our job to do the training and it is university's job to develop the understanding."

Another suggested that students saw the move from the drawing board to the computer as a natural progression. He also commented that unless they had experienced some board work initially,

“...they would have no awareness of the complexity of the system, no understanding of the view and, techniques to use the computer for - this way they appreciate the speed, the accuracy the training needed and the problems arising."

Teachers were asked to consider the advantages of going straight on to CAD and not covering any manual drafting/ technical graphics. It was suggested that greater motivation and interest through 'play' on the computer was something that could be exploited. Time gained could be used to work on CAD earlier in the school career. One teacher thought that although knowledge of orthographic was important prior to learning CAD "missing out the formal aspect of using the instruments is not important." Teachers were asked to identify what they felt children learned from manual technical drawing. Common features emerged and were categorised as follows:

'knowledge of fundamentals' (e.g. geometry and other aspects of layout, standards 
and conventions);

'cognitive'(e.g. interpretation of $2 d$ into $3 d$ and $3 d$ into $2 d$, measurement)

'psychomotor' (e.g. coordination, accuracy, line quality),

'attitudinal' (e.g. discipline, neatness),

'transferable skills' (e.g. planning on paper as if writing notes for essays, helped with sketching skills).

Views of Technology Student Teachers (sample group D) All technology student teachers thought that it was important to develop manual technical drawing prior to teaching CAD, but not necessarily essential. There was also a strong agreement that the transferable skills gained e.g. hand-eye co-ordination and fine motor skills, were of value beyond the CAD environment. Manual drafting was also considered to contribute towards developing creativity, individuality and improving freehand drawing. Analysis indicated that the student teachers felt that school students learned the 'basics' of engineering drawing better through manual technical drawing than directly on CAD. Basics tended to be described in terms of geometric construction techniques, line type and weight, layout, relationships between drawings, the importance of accuracy of measuring, scaling by eye, and general spatial awareness. Many placed value on the school students learning good practice and the 'housekeeping' requirements of drafting by working with the drawing instruments on the boards which contributes towards clean, easily interpreted and uncluttered meaningful drawings. The development of knowledge and understanding of these aspects could be missed altogether if school students were given no experience of manual drafting. These views echoed the views by the industry professionals, lecturers and teachers.

One student teacher offered that manual technical drawing helped the students learn"the finer details of drawings which are not always apparent on CAD drawings."Another felt the learning was more secure.

"I believe the pupils learn better.... with the different techniques and theory when using board work ....so that every pupil has it down in black and white instead of transferring files."

However, one student teacher thought manual drafting was important for exam purposes 
only.

The advantages of going straight on to CAD with no prior learning on the drawing boards were mainly connected to saving time in a crowded school syllabus with a limited timetable allocation. Some respondents, who favoured this, suggested that such an approach reflected more accurately what happened in industry where the emphasis is on vocational training rather than general education. Notably, those that indicated that time could be saved also commented that some key learning might be lost. Motivation, through the use of computers, was suggested as a plus. It was noted that "Some pupils are not comfortable / tidy/ clean / accurate enough to use boards-CAD does help with those processes for them."

Summary of Phases $1,2 a$ and $2 b$.

The data gathered from the professional CAD users, lecturers and teachers (sample groups A, B, C and D) clearly showed emerging themes and professional agreement between the various stakeholders from the world of work and education. These themes were further categorized to reflect key aspects of learning that had been identified:

1 cognitive development: understanding; thinking skills; spatial awareness, visualization skills; relationship of views of projection;

2 knowledge development: the application of basics of conventions, standards, layouts, drawing types, measurement and scale;

3 psychomotor development: coordination, control, accuracy, neatness and general discipline;

4. affective development: motivation, ownership, artistry, care, enjoyment. The next phase of the study explored the value of manual technical drawing from the perspective of the learner. 
Views of the school students (sample group E) This section describes the responses from school students who were surveyed. A positive, yet personal and realistic attitude seemed to prevail. In addition to responding to the 24 constructs provided, the majority (99\%) of the sample group $(\mathrm{n}=115)$ took time to complete the optional section of three open questions. Common themes emerged when the student responses regarding advantages of manual drafting were explored :

- easier to learn e.g.

“You don't have to be computer literate and you learn to appreciate the skills and efforts in technical drawing”; "You learn the basics quickly" "Don't crash, so you can't lose drawings"; "It is quick and accurate and you can see how you did the drawing because of the construction line."

- helps visualisation and setting out e.g.

"It gets you used to being able of drawing at different angles"; "It is easier to plan out your idea before finalizing them"; "easier to stop half way through and have a look and spot any mistakes."

- creativity, ownership and personalisation e.g.

\footnotetext{
"You can see what your own abilities are instead of what you can do on a computer." ; "I feel more involved" ;"It is more interesting and a challenge where you can take pride in your own work" ;"I think they look more skillful and impressive”; "it allows you to make it entirely your own”
}

Disadvantages of manual drawing were commonly identified as: messiness when making corrections, difficult to make changes, takes longer (after CAD has been mastered) and some things remain complicated to do manually. One student admitted with manual drafting " $a$ lot of concentration and work has to be applied."

Each year the number of students opting to take SQA Graphic Communication examination courses, at all levels, in Scotland, increases. This popularity indicates that there is continued 
interest in the courses among school students. The questionnaires provided some indication of how the students perceive their experience of manual technical drawing and CAD. The results of the analysis of the 24 constructs were clustered into five categories: 1 Order of learning As many as $87 \%$ of the student group, rising to $93 \%$ of the more experienced CAD users, agreed that it is better to have learned on drawing boards first. $78 \%$ agreed that you need to learn on the boards before going on to CAD.

$2 \quad$ Preference and enjoyment A significant majority (73\%) agreed CAD was more exciting than using the drawing boards, and clearly appreciated the inherent advantages of CAD. However, personal preference for manual technical drawing or CAD was split 50/50. Students also indicated a degree of enjoyment arising from the traditional drafting tools; $82 \%$ ( $78 \%$ of more experienced CAD users) agreed they like using pencil for various types of line conventions.

3 Control and ownership Students agree there is a greater level of control (78\% of respondents) and ownership (87\%) when working on the boards drafting with traditional instruments compared to CAD. Of the more experienced CAD users, 94\% agree that they can make the drawing more their own when drawing by hand rather than with CAD.

4 Usefulness of manual technical drawing and CAD. Two-thirds of the students agreed it was easier to visualise what they were drawing when using paper and pencil than on CAD. Of the more experienced students $71 \%$ agreed. There was a high level of agreement $(82 \%)$ that CAD helps them work more accurately and $77 \%$ agreed CAD makes their drawings better than they really are. One student conceded that CAD 'helps to make your drawings more sifisticated (sic)'

5 Learning and using CAD In general the student group was positive about learning to use CAD. The majority found it easy to learn and easy to use. However, there was a significant proportion (40\%) suggesting CAD was difficult and takes a long time to learn. There was no variation in this aspect when the more experienced sample was compared to the less experienced group. Mistakes could be found with equal ease on CAD as they were on the drawing board. They agreed it was important to stick to the rules and conventions working in CAD.

Further constructs provided additional views. Of the more experienced group $26 \%$ agreed that CAD was not very helpful for 'recording quick design ideas'. Students (54\%) indicated that they felt CAD was less useful than freehand sketching. This rises to $64 \%$ for the more experienced CAD users.

The students were clear as to why they should learn CAD: keeping up with the times, future career prospects and opportunities, variety, accuracy, efficiency, speed of production of quality output were the most common replies. They were able to articulate the value in learning traditional technical drawing. Their responses to the open questions offer a perceptive understanding of what they felt they were learning from the experience. The 
evidence suggests they are aware of the benefits of both and that both manual drafting and CAD have something to contribute. The insights gained from the survey indicate that the school students felt there was value in having experience and skills related to both CAD and manual technical drawing in order to have a personal and appropriate choice.

\section{DISCUSSION}

There appears to be a strong agreement between industry, teachers, and school students that there is still value in learning how to construct and draft technical drawings using instruments on the drawing boards. There was near consensus among all sample groups regarding a preferred route of progression in order to develop greater understanding of underpinning theories, conventions and geometry related to technical drawing. There was a strong preference for manual board work to precede CAD. The consensus is that this method allows the learner to grasp the operation of $\mathrm{CAD}$ quicker without being encumbered by learning, concurrently, basic aspects of layout, conventions and relationships between views.

The majority of those involved in teaching felt that it is easier to teach, and to learn, technical drawing and CAD as related, mutually supportive aspects of communication whilst also recognizing their separate and distinct techniques. The value in having skills related to both manual technical drawing and CAD was recognised by all sample groups. Some teachers felt it would be unwise to become too computer reliant. The ability to sketch orthographic rapidly, in relative scale with accuracy and clarity, for a variety of purposes, should be valued. There was also acknowledgement that it should be accepted that there was a need to be able to work, 'with real understanding', remote from CAD in far flung places as the job demanded. The school students too thought it important to have skills in both 'so that the general basics of drawing projection could be utilised if for some reason a computer was not available.' 
The data gathered suggested that manual technical drafting offers scope for greater individuality than $\mathrm{CAD}$ and creates a greater sense of achievement and a feeling of ownership. A significant majority of the school students surveyed indicated enjoyment and satisfaction in producing manual drawings. Whilst they appreciated the benefits of CAD, they agreed with professional CAD users that there is greater sense of artistry with manual drafting.

All sample groups were able to identify what learning was derived from manual technical drawing. This learning was not only identified in terms of fundamental knowledge, standards and conventions and techniques, but was also described in terms of personal gains too. The development of these transferable skills and attitudes can be categorized, in relation to related to Bloom's taxonomy of learning domains model (1965).e.g. general cognitive development: problem solving, thinking skills, spatial awareness, visualisation skills; psychomotor development : coordination, control, accuracy, neatness affective development : motivation, artistry, care, personal satisfaction.

The haptic experience of pencil and paper line production and layout, combined with the discipline of using orthographic and axonometric projections appears to engender a deeper appreciation of accepted conventions. These conventions seem to serve as an aid to developing visualisation skills required when engaged in mentally transposing images. In addition to those referred to in the first section of this paper, much has been written about the importance of developing the capacity for mental modelling and manipulation of images as a transferable skill (e.g. Bishop, 1986; Driscoll-Tole and McLaren, 1999; Outterside, 1996; Shepard, 1978; Cooley, 1988). Yet it remains a cognitive skill not adequately developed in the general school population.

History illustrates that there are no set doctrines in how to teach drafting, what to cover and what purposes technical / engineering drawing should must serve, as the debates of the late 1700s through to early 1900s illustrate [Monge,1795; Binns,1857; Cunningham,1868; 
Davidson, 1870; Harrison and Blaxandall, 1901 (in Brooker 1979)]. However, since the early 1900s drawing has been recognised, in higher education, not only as being of practical use but also as a cognitive development tool and a 'powerful engine of calculation'.

The introduction of any new technology creates debate and encourages review of curriculum provision at various levels of education. Livshits and Sandler (1999) provide a reminder that 'new inventions and tools usually come to strengthen and widen old ideas, not necessarily replace them.' They discuss problems in engineering education that lie in the imbalance of 'servant' subjects, computerisation and 'classic teaching of drawing'. (p79-80) They caution against computerisation as a panacea. Computers offer many advantages, but may not, in themselves, make a syllabus more relevant and of greater educational value. Further cautions have been offered by several authors over the last 20 years. For example, Cooley, writing in 1988, was concerned that there was uncritical acceptance of the CAD design outcomes and the ability in making qualitative judgements was potentially being discarded. He promotes teaching as more than technical training, but as the transmission of a culture that highlights the importance of nurturing human judgement, tacit knowledge, intuition and imagination at a time of technological advancement. Petrina (2003) cautions against accepting CAD as 'just another tool' and urges Technology teachers to rethink their approach and the content CAD (or Technical drawing). He argues for the adoption of a pedagogy that extends beyond the technical knowledge taught in isolation. He encourages Technology teachers to explore socio-technical issues; inter-relationships of technologies and societies, within their cultural contexts rather than an uncritical acceptance of the determinist model.

\section{CONCLUSION}

The findings from this research indicate that much can still be gained from taking time to develop underpinning knowledge and attitudes using teaching strategies that do not involve a 
computer. However, less time and practice on the drawing boards may be required than is currently demanded by Standard Grade Graphic Communication (1991). Increasing time spent on CAD may result in skilful CAD operators but at the expense of deep understanding. Graphic Communication, in general education, must be about more than merely training to use computer software packages and specific programmes.

This paper has not argued for the exclusive return to Euclid's methods of geometric construction. Curriculum evolution needs to be seen to be worthwhile and relevant for the learners, time and future it serves. In a digital society, efforts are made to review syllabi and incorporate, often uncritically, new technologies. The education system in Scotland is currently under wholesale review for all learners from 3-18 years old in order to improve the learning, attainment and achievement in the young people of Scotland in the $21^{\text {st }}$ century. 'Ambitious, excellent schools' (SEED, 2004) and 'A Curriculum for Excellence' (SEED 2004) demands a re-examination of the purposes of education and could result a radical overhaul of the curriculum.

This paper, as a 'case study', illustrates that using traditional tools and learning manual technical drawing is considered a worthwhile experience by a variety of 'stakeholders'. The argument to retain this experience, when it is rendered near redundant in the workplace, therefore can be justified in educational terms of validity, relevance, construction of knowledge and attitudinal development. Perhaps the questions of the staff room and web-ring debates, at this time of impending review, should not be are we teaching a redundant subject, but rather what is the purpose of our teaching and are we using a valid and relevant pedagogy?

APPENDIX 1 About you (please circle): MALE / FEMALE Standard Grade S3 Standard Grade S4 Int 2 Higher

Please indicate, with a tick, your opinions: Strongly agree

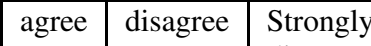
disagree 
Bhavnani, S.K., \& John, B.E. (1997). From Sufficient to Efficient Usage: An Analysis of Strategic Knowledge. In Conference Proceedings of CH1'97, 91-98.

Bhavnani, S.K., Reif, F. \& John, B.E. (2001). Beyond command knowledge: Identifying and teaching strategic knowledge for using complex computer applications. In Conference Proceedings of CH1'01, 229-236

Bishop, A. J. (1986). What are some obstacles to learning geometry? Studies in mathematics education: The teaching of geometry 5, 141-159

Bloom, B. (1965). Taxonomy of educational objectives: The classification of educational goals. New York: David McKay Company, Inc.

Booker, P. F. (1979). A History of Engineering Drawing. Bury St Edmonds: Northgate

Bussey, J., Dormody, T.V. \& VanLeenwen, D. (2000). Some factors predicting the adoption of Technology in New Mexico Public Schools Journal of Technology Education 12, 1, 4-17 retrieved October 2006 from http://scholar.lib.vt.edu/ejournals/JTE/v12n1/pdf/index.html Cooley, M. (1988). From Brunelleschi to CAD-CAM. (In J. Thackara (Ed.), Design After Modernism (pp.197-207) London: Thames and Hudson)

Circular 1101: Implementation of the Government's proposal for the reform of the Curriculum and Assessment in S3 and S4, 2 Dec 1983 SED: HMSO

Chester, I. (2004). Teaching CAD: A Snap or Are we Missing the point? (In H. Middleton, M. Pavlova and D. Roebuck (Eds) Learning for Innovation in Technology Education 1 
(pp113-121) Queensland :Griffith University)

Devon, R., Engel, R. S., Foster, R. J., Sathianathan, D., \& Turner, G. F. (1994). The effect of solid modeling software on 3-D visualization skills. Engineering Design Graphics Journal, $5,8,(2), 4-11$

Entwhistle, N. (1981). Styles of Learning and Teaching; an integrated outline of educational psychology for students, teachers and lecturers. Chichester: John Wiley

Field, D. (2004). Education and training for CAD in the auto-industry. Computer-aided Design. 36, 1431-1437

Gagel, C. W. (1997). Literacy and technology: Reflections and insights for technological literacy. Journal of Industrial Teacher Education, 34(3), 6-34.

Haapasalo, H. (2000). Creative Computer aided architectural design - an internal approach to the design process. Academic Dissertation presented to Faculty of Technology, University of Oulu, Finland: Oulun yliopisto Retrieved Oct 2006 from http://herkules.oulu.fi/isbn9514257545/

Hughes, L. (2003). Manual Drawing in School. Unpublished PGCE Assignment, Glasgow: University of Strathclyde

Livshits, L. \& Sandler, B.Z. (1999). Upstairs/Downstairs in Technical Education: The unsettling effects of computerization. International Journal of Technology and Design Education 9, 1, 73-84. 
Leopold, C., Gorska R, \&. Sorby, S. (2001). International Experiences in Developing the Spatial Visualization Abilities of Engineering Students. Journal for Geometry and Graphics 5, $1,81-91$.

Marton, F. \& Säljö, R. (1976). "On Qualitative Differences in Learning 1: Outcome and Process" British Journal of Education Psychology, 46, 4-11

McCardle, J. (2002). Back to the Drawing Board. The Journal of Design and Technology Education 7, 2, 123-132.

O’Driscoll-Tole, K., \& McLaren, S.V. (1999). A Shared Agenda-establishing a dialogue between mathematics and technology.( in N.P. Juster (Ed) The Continuum of Design Education (pp.101-117). Wiltshire: Cromwell Press)

Olkun, S. (2003). Making Connections: Improving Spatial Abilities with Engineering Drawing abilities. International Journal of Mathematics Teaching and Learning 1-10. Retrieved October 2006 from http://www.cimt.plymouth.ac.uk/journal/sinanolkun.pdf Outterside, Y. (1996). Can young children rotate an image on 3D block and consequently make a prediction based on this mental rotation? Can they also see from another's point of view? ( In J. Smith\& P. Roberts (Eds) IDATER Conference Proceedings (pp.53-58) Loughborough)

Petrina, S. (2003). Two Cultures of Technical Courses and Discourses: The case of Computer Aided Design. International Journal of Technology and Design Education 13, 1, 47-73.

Prensky, M. (2001a). Digital Natives, Digital Immigrants. On the Horizon 
9, 5. NCB University Press Retrieved Oct 2006 from

http://www.marcprensky.com/writing/Prensky\%20-

\%20Digital\%20Natives,\%20Digital\%20Immigrants\%20-\%20Part1.pdf

Prensky, M. (2001b). Digital Natives Digital Immigrants Part 2: Do they really think differently? On the Horizon 9, 6. NCB University Press retrieved Oct 2006 from http://www.marcprensky.com/writing/Prensky\%20\%20Digital\%20Natives,\%20Digita 1\%20Immigrants\%20-\%20Part2.pdf

Reffold, R.N.(1998). Teaching and Learning Computer-Aided Engineering Drawing. International Journal of Engineering Education 14, 4, 276-281 Scottish Executive Education Department (2004). Ambitious, excellent schools: an agenda for action. Edinburgh: SEED

Scottish Executive Education Department (2004). A Curriculum for Excellence. Edinburgh: SEED

Scottish Qualification Authority. Standard Grade Graphic Communication (1991 for in and after 1993) Dalkeith: SQA

Scottish Qualification Authority. Intermediate 2 Grade Graphic Communication (in and after 1999) \& Higher Grade Graphic Communication (in and after1999)

Dalkeith: SQA

Scottish Qualification Authority. Advanced Higher Grade Graphic Communication (in and after 2000) Dalkeith: SQA 
Scottish Education Department. (1972). Technical Education in Scottish Schools: Curriculum Paper 10, Scottish Education Department SED: HMSO

Shepard, R.N. (1978).The Mental Image. American Psychologist 33, 125-137.

Sorby, S. \& Gorska, R. (1998). The effect of various courses and teaching methods on the improvement of spatial ability. Proceedings of 8th ICEDGDE, Austin Texas, 252-256 Ullman, D., Wood, S. \& Craig, D. (1990). The Importance of Drawing in the mechanical design process Computer and Graphics 14, 2, 263-274 Retrieved Oct 2006 from http://web.engr.oregonstate.edu/ ullman/drwg.htm

Wiebe, E. N. \& Clark, A. C. (October, 1997). Evolving Technical Graphics in the High Schools: 2. A New Curriculum in Scientific Visualization. Presented at the ASEE-EDGD Mid-Year Meeting, North Carolina State University Raleigh, NC. Retrieved Oct 2006 from http://www4.ncsu.edu/ wiebe/www/articles/svc-1997.pdf 